\title{
Indicators of Quality in the Logistics Sector of Organic Products ${ }^{\dagger}$
}

\author{
Lais Alves ${ }^{1, *}$, Felipe Velihovetchi ${ }^{2}$, Elaine Vazquez ${ }^{3}$ and Alexandre Ali ${ }^{4}$ \\ 1 Department of Mechanical Engineering, Federal Center of Technological Education Celso Suckow da \\ Fonseca (CEFET/RJ), 20271-110 Rio de Janeiro, Brazil \\ 2 Department of Civil Engineering, Federal Center of Technological Education Celso Suckow da Fonseca \\ (CEFET/RJ), 20271-110 Rio de Janeiro, Brazil; felipe.vetchi@gmail.com \\ 3 Department of Civil Construction, Federal University of Rio de Janeiro (UFRJ), 21941-909 Rio de Janeiro, \\ Brazil; alexandre.ali@cefet-rj.br \\ 4 Department of Administration, Federal Center of Technological Education Celso Suckow da Fonseca \\ (CEFET/RJ), 20271-110 Rio de Janeiro, Brazil; elainevazquez@poli.ufrj.br \\ * Correspondence: lais.alves@cefet-rj.br \\ + Presented at the 5th Ibero-American Congress on Entrepreneurship, Energy, Environment and \\ Technology-CIEEMAT, Portalegre, Portugal, 11-13 September 2019.
}

Published: 26 December 2019

\begin{abstract}
In recent years, the increasing supply of food products has generated a higher level of demand among consumers. In consideration of the immense variety of brands, types and prices, quality has ceased to be a competitive differential, becoming a necessity for those who want to stay in the market. Thus, the search for quality has become a goal for everyone within the companies. This project aims to demonstrate the importance of quality in the food industries and the processes adopted to help small businesses to maintain advantages, keeping accessible prices. The methodology described, includes the generation of standardized documents and the analysis of the results brought by adopting quality management. As a result, the paper shows a reduction of 4.6 ton of $\mathrm{CO}_{2}$ launched at the atmosphere by adapting the logistic section of 13 small organic food businesses.
\end{abstract}

Keywords: quality; sustainability; $\mathrm{CO}_{2}$; organic products; human resources

\section{Introduction}

The project discusses food quality and safety standards that are extremely important, not only for consumers but also for economic development, where consumer safety is among the key issues to consider in managing the food supply chain. It aims to demonstrate the importance of quality in the food industries and the processes adopted to stand out and stay in the market. Throughout a case study, the paper aims to demonstrate the importance of quality and logistics applied to the food industries.

\section{Logistics and Quality}

The idea of quality as a competitive advantage began to emerge from the 1970s with models developed by the American consultant W.E. Deming - considered the father of quality. Disbelieved in his home country, he saw his concepts applied mainly to Japanese industry with immense success [1].

Quality is perceived differently by different people. However, everyone understands what it means. In a manufactured product, the customer, as a user, recognizes the quality of appearance, function and performance. Quality of service can be assessed based on the degree of customer 
satisfaction that receives the service. The relevant meaning of the quality dictionary is "the degree of excellence" [2].

However, this definition is of a relative nature. The final test in this assessment lies with the consumer. Customer needs must be translated into measurable characteristics of a product or service. Once specifications are developed, ways to measure and monitor characteristics need to be found. This provides the foundation for continuous improvement of the product or service. The ultimate goal is to make sure the customer is satisfied with the product or service. This should result in a reasonable profit for the producer or service provider. The relationship with a customer is long lasting. The reliability of a product plays an important role in the development of this relationship. [3].

Given the diversity of characteristics found in food products, product quality can be assessed from two points of view: objective and subjective. From an objective point of view, product quality refers to the intrinsic or hidden characteristics of the product, i.e., the nutritional and hygienic characteristics of the product, which are characteristics not perceived by consumers, but which compromise their health. And from a subjective point of view, product quality refers to consumer preference characteristics such as shape, smell, taste, texture, practicality and appearance that, while not compromising consumer health and safety, interfere with the decision whether or not to purchase the product [4].

Certification plays an important role in the buying and selling relationship since food quality and safety cannot always be assessed directly. In fact, certification reduces uncertainties regarding product quality by providing information about the product and about production and its process. In the specific case of in natura organic products, certification guarantees to intermediaries and consumers, which prove that the products are really organic (pesticide free), and do not harm the environment, and this slave labor or equivalent is not employed in their production. On the other hand, certification does not guarantee characteristics such as shape, texture, taste, appearance, other words, characteristics perceived by the consumer. Needless to say, the absence of these features can affect the purchase decision [5].

While certification is an efficient mechanism for customer and consumer information asymmetry, especially for certain product attributes, it does not guarantee other aspects of agreement between seller and buyer. In other words, regular trading, trading conditions (price, terms, payment) and access to other markets is not guaranteed [6].

In addition, in Brazil, the organic products segment has to deal with obstructions in production, marketing and institutionalization [7]. Market access and often uncertain price premiums, even in foreign markets, should be emphasized [8]. Small producers have huge difficulties in accessing large markets (supermarkets and specialty food stores), while chains prefer marketing deals involving fresh organic produce with large producers due to lower transaction costs and more competitive prices [9].

\section{Project Gaia}

The Gaia project aimed to introduce a new market and logistics model to small producers throughout Brazil. It consists on an innovative proposal to change the logistics of small organic producers in the state of Rio de Janeiro. Through a collaborative network, known as "Comida da Gente" ("Food of the People"), a new possibility for sale and exposure is presented to producers.

\subsection{Enactus Network}

Enactus is a worldwide non-profit organization made up of young college students, teachers and business leaders that aims to develop social entrepreneurship projects to empower people living on the fringes of society [10].

Enactus projects are made on top of 3 parameters. (1) Projects must contribute socially to the community and beneficiaries in which they are present directly or indirectly. (2) Projects must be sustainable and environmentally friendly, i.e., they need to have zero or positive environmental impact. (3) Projects need to have a positive economic impact on the beneficiaries. In addition to the 
parameters, all projects have to be sustainable, that is, after the project ends, lasting around 2 years, and the gradual withdrawal of the community team the beneficiaries must be able to keep alone the benefits gained with the help of the project. project and continue to develop [11].

Enactus Cefet/RJ was founded in 2002. The team has been conducting social entrepreneurship projects for 16 years to improve the quality of life of various communities [11].

\section{2. "Comida da Gente" Network Operation}

"Comida da Gente" is a social network that connects producers to consumers, that is, a buying and selling network. This network operated exclusively through a Facebook group, where a producer advertises their products on a list and participants express interest. In the next step, the interested participants make the payment and organize themselves to do the distribution logistics collaboratively.

All the dynamics proposed by the network, which uses a new way to perform distribution logistics, brings several benefits. For the least-moving producer, increasing their quality of life and profitability in their sales, and for the lower-paying customers, due to the exclusion of the intermediate, who previously profited from logistics, and is able to have closer contact with the producers. During the project, several problems were identified that diminished the efficiency of the network.

\subsection{Lack of List Standardization}

Each producer, when creating a list on the "Comida da Gente" network created their own spreadsheet where they offered their products. These spreadsheets were not standardized for all producers, which made it difficult for consumers to understand their operation. Often causing them to give up the purchase or filling it in the wrong way, causing disagreements between the parties and making the sale difficult.

Through a study of all the spreadsheets already used in the network, the team Enactus Cefet/RJ identified the needs and developed a standard spreadsheet that served all producers and consumers. This spreadsheet facilitated the marketing of products by making the buying and selling process more efficient and simplifying order errors.

Após a criação da lista padrão foi feito treinamento dos agricultores para eles preencherem corretamente a mesma e venderem seus produtos e divulgação de material de apoio para a utilização das listas. Além disso foi criada a equipe de suporte para tirar dúvidas sobre a lista padrão e auxiliar tanto os vendedores como os compradores.

In Figure 1, an increase in list opening can be identified which results in an increase in product offerings where it jumped from 11 lists in January 2015 to over 45 lists in December of the same year showing a tendency of increase.

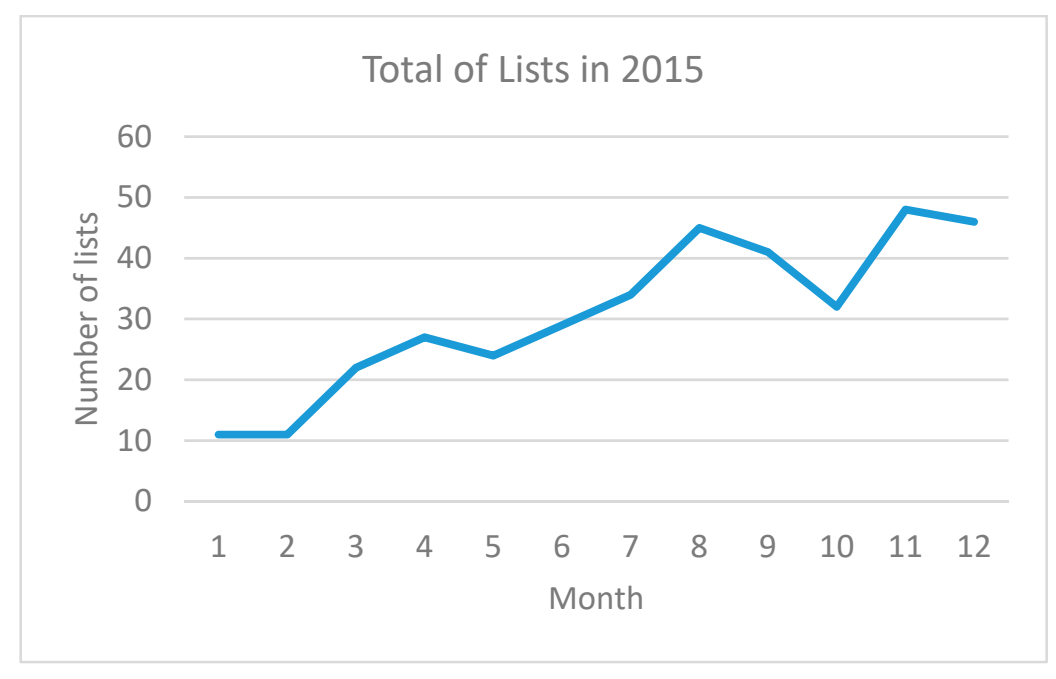

Figure 1. Total of lists in 2015. 
In 2015, the month with the largest list opening was in November with 48 lists. The default list was not yet used. In 2016 (0), a considerable increase in the number of open lists can be observed, averaging 46.75 lists per month, almost reaching the best month of the previous year, with 48 lists and average $30.83(0)$.

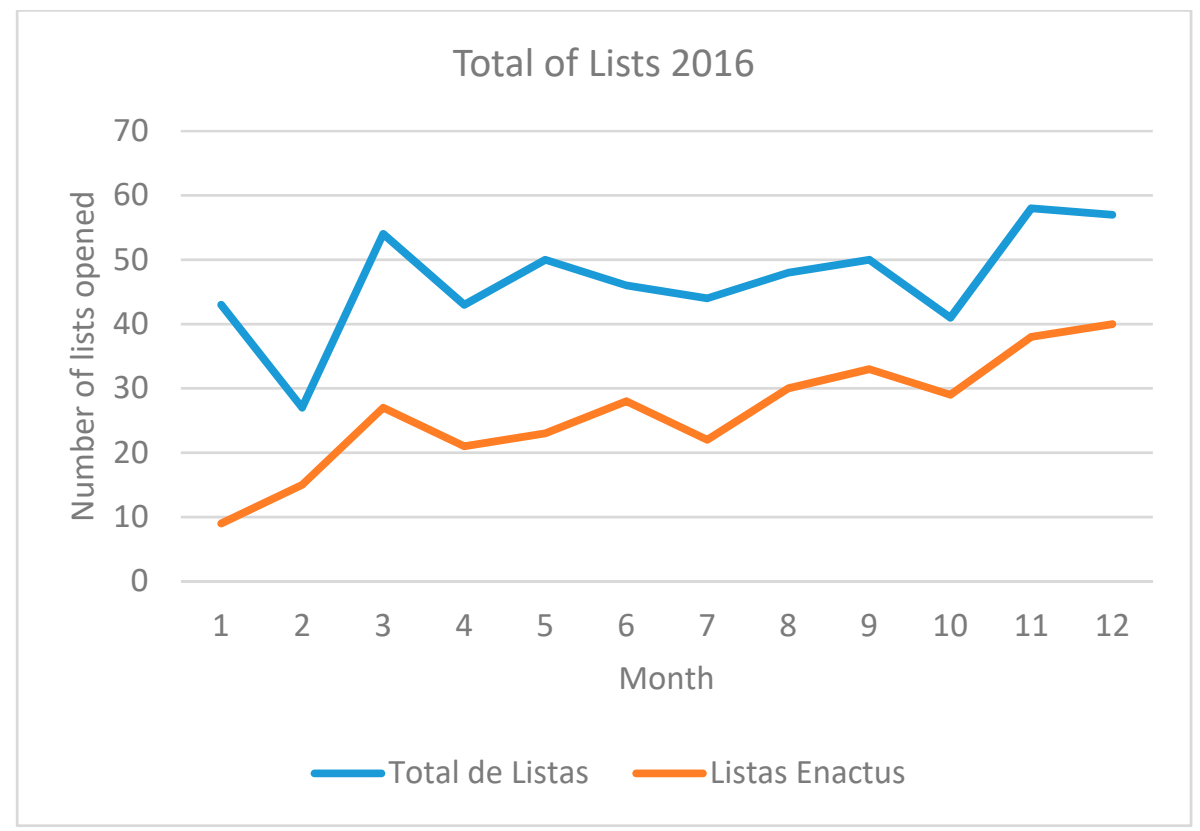

Figure 2. Total of lists 2016.

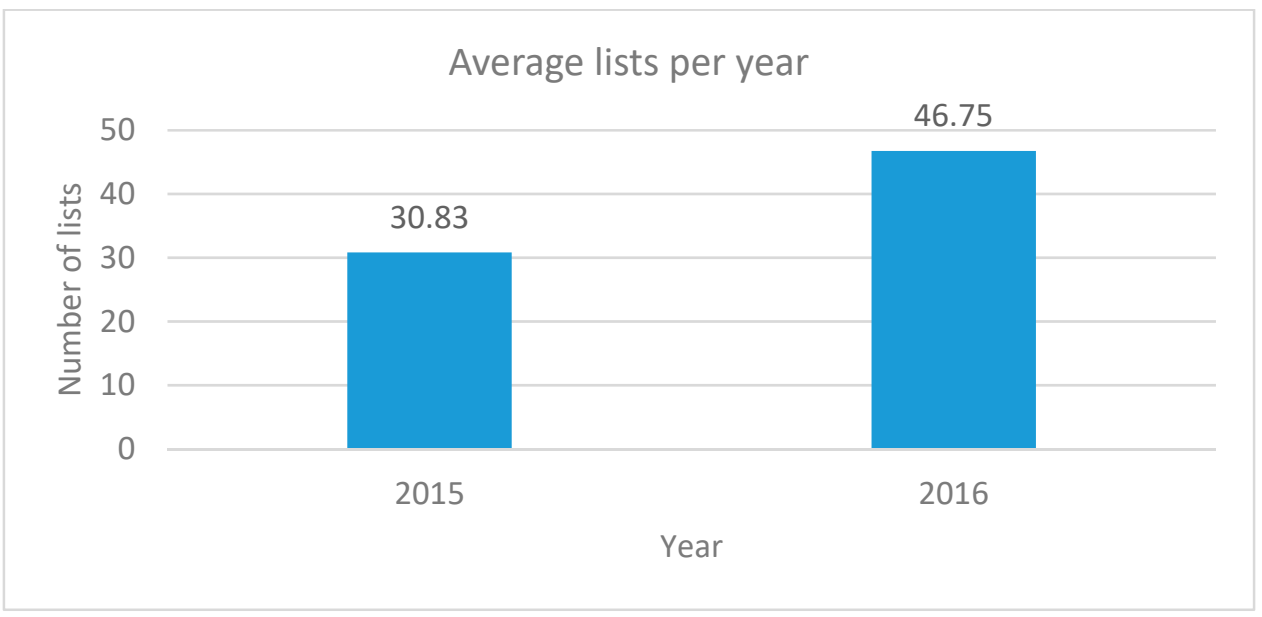

Figure 3. Average of lists per year.

In 0 , a decrease in the number of non-standard lists used can be observed. It can be said that the standard spreadsheet was being adopted and accepted by the producers. 


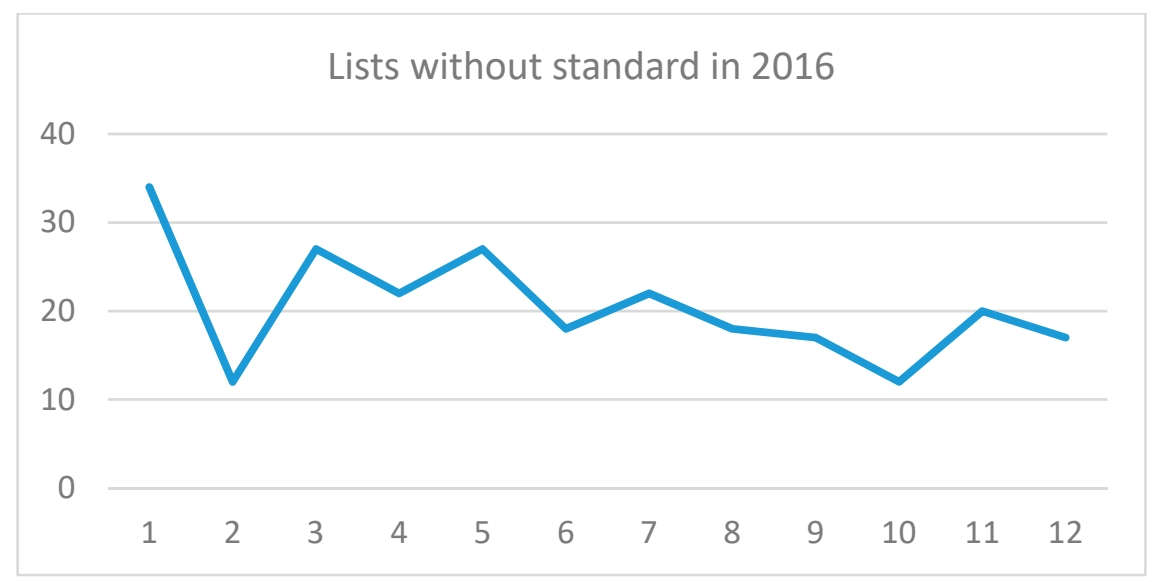

Figure 4. Lists without standard in 2016.

\subsection{Lack of List Standardization}

The platform used to make the rapprochement between the producer and consumer and later the trade of its product was facebook, which does not have as its objective and purpose this type of use. As a result, there was a lack of organization and a difficulty for producers to expose their product lists and consumers to find and research available products. Due to the large supply and demand, on the facebook page, many publications with product offerings were not seen, because facebook does not organize the publications by their dates and this led to a reduced number of sales. Comments were needed on publications to make them more visible to consumers, making it difficult to sell to people who did not have easy access to the Internet.

To solve this problem a platform was created through the site "https://comidadagente.com/" focused and fully prepared for the commercialization mainly of organic products and their derivatives. This platform is still in the testing period, but already has products being offered by small and medium producers, search engine options, larger organization as producers and consumers registration, optimized payment method with more options such as credit card and security, through the "Bcash" system.

\subsection{Lack of Organic Certifications on Products}

Most farmers in the group belong to a family farm that is passed on from parent to child and, due to their low level of education and knowledge, saw no need to take organic stamps to increase credibility and add value to their products. Awareness was raised by training with producers so that they sought to certify their products in order to ensure its quality and increase its added value. With the increase in the number of products and certified producers in the group, sales of these producers increased and those who had not yet certified sought to take certifications.

\subsection{Producers' Difficulty on Creating Lists}

Many producers who did not have an organizer, a person who organized and created lists for a group of small farmers for free or received a symbolic fee for the service, found it difficult to create their lists and sell their products. To solve this problem the supporters were created on the platform, which were volunteers, mostly members of Enactus Cefet/RJ, prepared to assist these producers by answering their questions. Supporters remotely opened the lists together with the producers, always teaching them how to do each step until they started opening their lists on their own. Supporters also prepared standard product texts with all the necessary information and assisted in marketing them. In addition to support, video lesson training on how to open product offer lists was prepared.

\subsection{Small Offers from Producers}

To increase the number of producers inserted in the network, a large marketing campaign was made to publicize the page on facebook and increase the number of product offerings. With the 
increase in the number of lists and consequently sales, the platform, still on facebook, grew and expanded to other cities and states. Subsequently with the creation of the site and optimization of the advertising and sales system through sign-ups, safer payment methods, more intuitive page, the number of products offered grew.

\subsection{Logistics Problem}

To make the distribution, the producers marked points of withdrawal, which were often scarce and did not serve a large area of the city and thereby missing out on great sales opportunities. To minimize this problem the shifters were created, people who when entering a list, offers to move to places where they usually go (work, home, etc.). He will be responsible for picking up the products at the place of delivery so that participants who live or work near him can pick up their orders. Shifters promote access to products that some participants might not have. In addition to the shifters, several withdrawal points were created together with small traders and subsequently the organizing role was created, which is responsible for managing a Community or Purchase Campaign. You can be a participant who wants to create a Purchasing Community, who is interested in a specific product and wants to organize a Campaign, or even the producer himself. The organizer, in addition to starting a Campaign, receives the products at their pickup point, separates the orders and organizes the withdrawals. He receives $7.5 \%$ of the Campaign value for his work.

By using shifters, who did not go out of their daily route to distribute products, there was no extra emission of polluting gases into the atmosphere. In 13 lists, $2025.5 \mathrm{~km}$ were traveled by the displacers, avoiding the release of 4.6 tons of $\mathrm{CO}_{2}$ into the atmosphere, using a 1.0-valve, 16-valve car powered by gasoline and using the $\mathrm{CO}_{2}$ emission calculator from the "green initiative" website.

\section{Final Considerations}

The competitiveness of a company can be seen as a reflection of the strategies adopted which means adapting to the competition rules prevailing in the markets in which the organization operates. Certainly, quality is a key factor for the food industry, operating in an increasingly globalized market. For this, companies must establish competitive strategies and develop an appropriate internal structure.

From these assumptions, this project discussed about the importance, as well as specific aspects, quality management in the food industry. The reality of each company, in terms of financial, cultural, organization and motivation, will determine the degree of maturity and efficiency in quality management. What can be concluded is that the competitive advantage certainly involves the constant search for new tools and learning management systems that prove the quality of processes and services, consequently the products offered by the food industry.

However, marketing of organic product channels in Brazil has demonstrated the importance of this activity and marketing not only for small, medium and large farms, but also different types of certification (third parties and GPS). The relevance of marketing channels, such as supermarkets and any size, also reveals the importance of collective activities among smaller producers, aiming at greater aggregation of the product through delivery to the public specialized in fairs and between medium and large producers, aiming at greater aggregation of information and knowledge with better bargaining capabilities, including with retail chains and intermediaries.

\section{References}

1. Martins, V.A.; Camargo, W.P.; Fernando, Bueno, C.R.F. Preços de frutas e hortaliças da agricultura orgânica no mercado varejista da cidade de São Paulo. Inf. Econ. 2006, 36, 42-52.

2. Forza, C. Survey research in operations management: a process-based perspective. Int. J. Oper. Prod. Manag. 2002, 22, 152-194. doi:10.1108/01443570210414310

3. Elder, S.D.; Lister, J.; Dauvergne, P. Big retail and sustainable coffee: A new development studies research agenda. SAGE J. 2014, 14, 77-90. doi:10.1177/1464993413504354.

4. Vorley, B.; Fox, T. Global Food Chains: Constraints and Opportunities for Smallholders; OECD: Paris, France, 2014. 
5. Machado, R.T.M. Rastreabilidade, Tecnologia da Informação e Coordenação de Sistemas Agroindustriais. Ph.D. Thesis, Universidade de São Paulo, São Paulo, Brazil, 2000.

6. Scalco, A.R.; Servi, R.G. Manutenção da certificação orgânica em propriedades rurais. Rev. Agron. Meio Ambiente 2014, 7, 515-534.

7. Blanc, J. Family farmers and major retail chains in the Brazilian organic sector: Assessing new development pathways. A case study in a peri-urban district of São Paulo. J. Rural Stud. 2009, 25, 322-332.

8. Fonseca, M.F.A.C.; Barbosa, S.C.A.; Colnalgo, N.G.; Silva, G.R.R. Agricultura Orgânica: Introdução às Normas, Regulamentos Técnicos Critérios para Acesso aos Mercados dos Produtos Orgânicos no Brasil; Programa Rio Rural: Niterói, Brazil, 2009; p. 58.

9. Blanc, J.; Kledal, P.R. The Brazilian organic food sector: prospects and constraints of faciliting the inclusion of smallholders. J. Rural Stud. 2012, 28, 142-154.

10. ENACTUS. Available online: https://enactus.org (accessed on 10 December 2018).

11. ENACTUS Cefet/RJ. Available online: http://enactuscefetrj.com/ (accessed on 10 December 2018).

(C) 2019 by the authors. Licensee MDPI, Basel, Switzerland. This article is an open access article distributed under the terms and conditions of the Creative Commons Attribution (CC BY) license (http://creativecommons.org/licenses/by/4.0/). 